\title{
Augmentation of Learning Through The Use of Simulation Tools \& Techniques in Under-graduate Metal Forming Course
}

\author{
Praveenkumar M Petkar ${ }^{1}$, N. Vijay Kumar ${ }^{2}$, Gururaj.Fattepur ${ }^{3}$ \\ ${ }_{123}$ Dept. of Industrial and Production Engineering, \\ B. V. B. College of Engineering and Technology, Hubballi, \\ Karnataka \\ 1praveenkumar@bvb.edu \\ 2 vijaykumar@bvb.edu \\ 3gururaj_f@bvb.edu
}

Abstract:

Experiential/activity based learning is the process of learning through doing an activity and is thought to be useful to increase the retention of theoretical concepts and will help in bridging the gap between theory and practice. The inspiration for this work is the fact that learning can be fruitful only when the class-room theoretical concepts are visualized/ experienced through laboratory practice and is the essence of experiential/activity based learning teaching practices. The attempt has been made to bridge the gap between theory and real-time industry practices by means of open ended activity learning for the undergraduate course of $\mathrm{V}$-semester Manufacturing Technology- Metal Forming. In today's era numerical simulation as a component of the virtual manufacturing concept of sheet metal forming has emerged as one of the important processes in manufacturing technology. This has resulted in reduced lead time and increased product quality. To inculcate these concepts to the students for a better understanding, a metal forming simulation software has been incorporated as part of this activity. Here student groups identified the sheet metal components (which included the sheet metal forming operations like shearing, bending, deep-drawing, etc.). They carried the design, modeling, simulation, analysis and interpreted the results. This activity not only helped students to get acquainted with the design process, but also lead to better understanding of class-room theoretical concepts. A close resemblance is experienced by students between the simulation results and theoretical calculation which resulted in cognitive and synergic atmosphere for learning among the students and by this the outcome b-"Ability to design and perform laboratory experiments for manufacturing \& allied systems as well as to analyze and interpret data" of ABET $3 \mathrm{~b}$ has been achieved.

\section{Corresponding Author}

Praveenkumar M Petkar.

Department of Industrial \& Production Engineering, BV

B College of Engineering \& Technology, Hubli 580031

Email: praveenkumar@bvb.edu

Keywords: experiential learning, open ended exercise.

\section{INTRODUCTION}

Experiential learning is referred to as learning through action, learning by doing, learning through experience, And learning through discovery and exploration.[1] The traditional classroom situation is such that the students would compete with one another or remain uninvolved or unmotivated and the instruction is highly structured, students in experiential learning situations cooperate and learn from one another in a more semistructured approach. Instruction is designed to engage students in direct experiences which are tied to real world problems and situations in which the instructor facilitates rather than directs student progress[2]. Here the attempt is made to connect theoretical concepts through practicing; simulating the process using simulation tools. Manufacturing technology is one such course which includes material shaping techniques to attain the desired configuration of the product/part. These concepts are even-though well explained through visual aids and other techniques; the augmentation of learning happens when, students would grasp better with practice, when there is active participation of the students by engaging them with a kind of designing and simulation of these processes through the laboratory experiments. In the process, students would be well exposed to virtual manufacturing concepts, design and analysis process and would lead to better understanding of the theoretical concepts when, they do the comparison between hand calculations and simulation results.

\section{A. Sheet Metal Forming}

Sheet metals are widely used for industrial and consumer parts because of its capacity for being bent and formed into intricate shapes. Sheet metal parts comprise a large fraction of automotive, agricultural machinery, and aircraft components as well as consumer appliances. Successful sheet metal forming operation depends on the selection of a material with adequate formability, appropriate tooling and design of the part, the surface condition of the sheet material, proper lubricants, and the process conditions such as the speed of the forming operation, forces to be applied, etc. A numbers of sheet metal forming processes such as shearing, bending, 
stretch forming, deep drawing, stretch drawing, press forming, hydro-forming etc. are available till date. Each process is used for a specific purpose and the requisite shape of the final product. Sheet metal working has also been greatly influenced by this simulation tool. The industrial performance has been increased by the influence of virtual manufacturing concept in terms of reduced manufacturing time and improved product quality. Simulation tool/technique as a component of virtual manufacturing helped in reduced lead time with increased product quality. The fig. 1 shows the sheet metal components and press tools. [3,4]

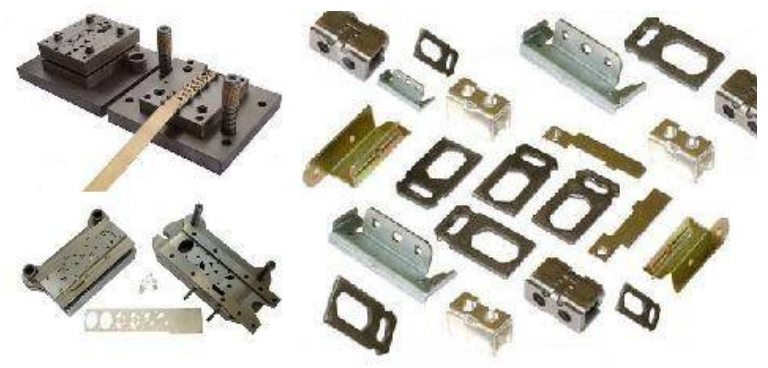

Fig. 1. Sheet metal components and press tools

\section{OBJECTIVES}

a) To bridge the gap between theoretical concepts and real time practice.

b) To orient virtual manufacturing concepts through simulation of the processes.

c) To get acquainted with the design and analysis process.

d) To expose to the real industry practices.

\section{METHODOLOGY}

The students were initially oriented with the use of simulation software with basic standard experiments on bulk deformation processes (like forging, rolling extrusion) and sheet metal working (shearing, bending, and deep-drawing) with all necessary inputs required for simulation; details of material \& dies, friction, working temperature, stroke/velocity etc., Then with an introduction of open-ended experiment, students were asked to carry-out design and analysis of simple sheet metal components, which included shearing, bending, deep-drawing operations. A batch of four students is been made with total seventeen groups have been formed ,each batch need to identify the sheet metal component and design the punch, die ,work piece and simulate the design and interpret the results using simulation tool.

The details of different process to be followed in analyzing the sheet metal components are as follows.

Design: Design phase includes the component analysis, selection of suitable operation, determining the punch and die dimensions, and preparing the 3D solid models for simulation (Modeling) [5].
Conduct: Once 3D models are prepared, these models are imported in to the simulation environment of the software and material, stroke, friction details need to be assigned. Then with all these inputs simulation is carriedout. This can be summarized as pre-processing and post processing

Analyze: The simulation results are observed for four of the important aspects of forming. Such as

i. Effective Strain

ii. Effective Strain Rate

iii. Effective stress

iv. Load $\mathrm{v} / \mathrm{s}$ stroke diagram

Interpret: Amount of deformation, rate of deformation, selection of press, die strength, defect detection is evaluated based on the analysis results and are compared with theoretical calculations.

A close resemblance is experienced by the students between simulation results and theoretical calculation viz., calculation of force required to deform/shear, selection of press, die structural analysis for determining the strength of the die, rate of deformation.

\section{STUDENTS' PROJECTS}

The problem statement for the open ended experiment is given as "Design, modeling and analysis of sheet metal component of industry/domestic application".

This title indeed is an open statement for students to identify the sheet metal components, which include blanking, piercing, bending and deep-drawing operations and could connect the experience with real world examples; to find trends or common truths in the experience, and identify "real life" principles that emerged.

Some of sheet metal components are identified by the students to carry-out design of punch \& dies and simulation of the process is as shown in fig. 2
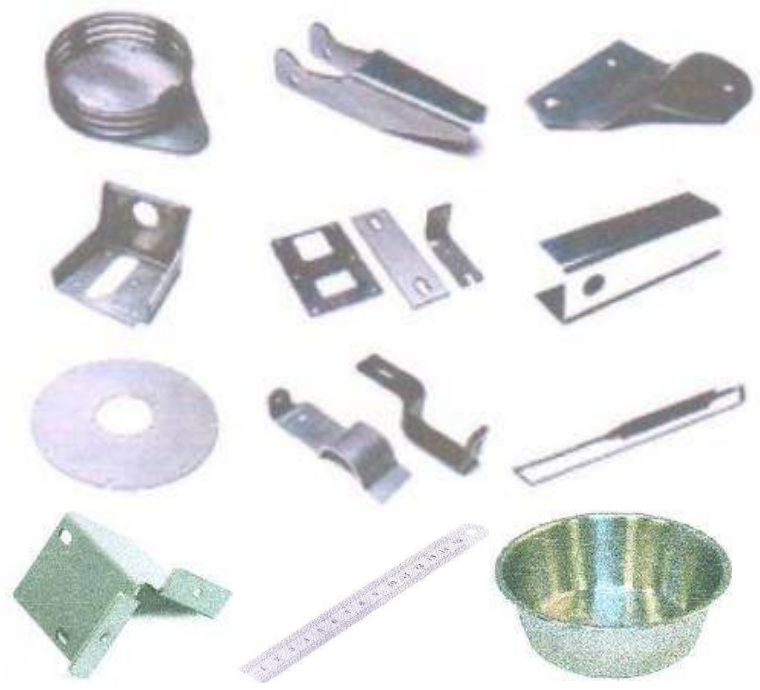

Fig.2. Simple sheet metal components identified by the students 


\section{Open ended experiment 1:}

Title: "Design and simulation of Stainless Steel Cup (Deep-drawing Process)".

\section{Design:}

With regard to the component analysis, the sheet metal component identified is a domestic kitchenware articlestainless-steel cup of diameter $65.0 \mathrm{~mm}$, height of $45.0 \mathrm{~mm}$ and $1.0 \mathrm{~mm}$ thick made-up of deep drawing process. The design calculation includes determining the punch and die dimensions taking into consideration of clearance between the die and punch, force and preparing the $3 \mathrm{D}$ solid models for simulation as part of Modeling, shown below in fig. 3 .
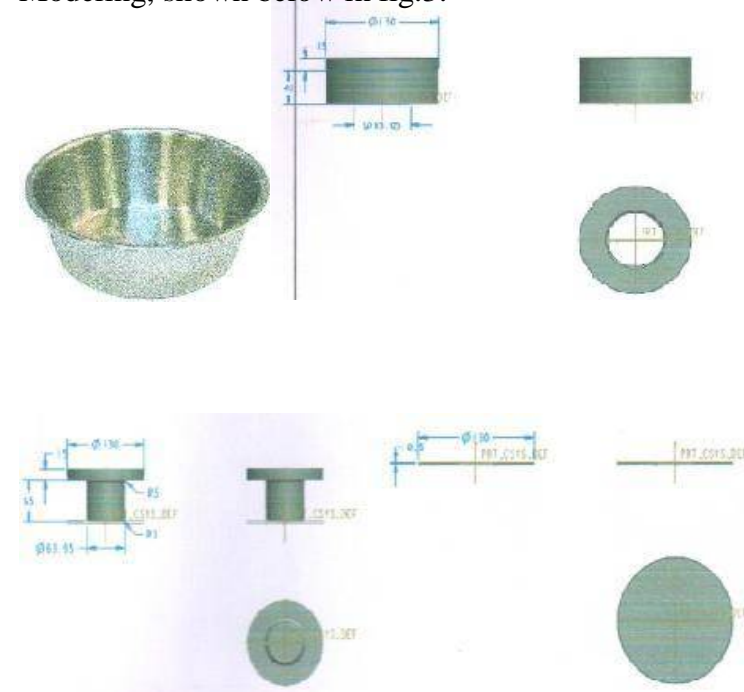

Fig. 3. Stainless steel cup component and punch $\&$ die models.

Conduct: After the modeling of the punch, die and workpiece, models are imported into the simulation environment of the software and essential input details are assigned such as material, stroke, friction details. Then with all these inputs, simulation is carried-out.

Analyze: The simulation results are observed in four of the important aspects of forming given in the table 1

Table 1. Observation of the deep drawing simulation

\begin{tabular}{|c|l|l|l|}
\hline S.No. & Description & Unit & Max. Value \\
\hline 1 & Effective Strain & $\mathrm{mm} / \mathrm{mm}$ & 1.621 \\
\hline 2 & Effective Strain Rate & /second & $0.5255 / \mathrm{s}$ \\
\hline 3 & Effective Stress & $\mathrm{MPa}$ & 801.3 \\
\hline 4 & Load v/s Stroke & Ton v/s s & 4.469 \\
\hline
\end{tabular}

The simulation screen-shots is shown in fig. 4(a) and (b).
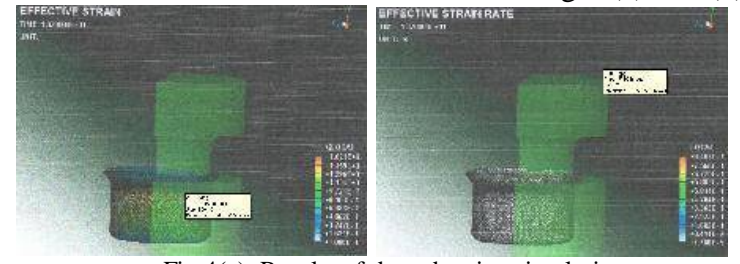

Fig.4(a). Results of deep drawing simulation

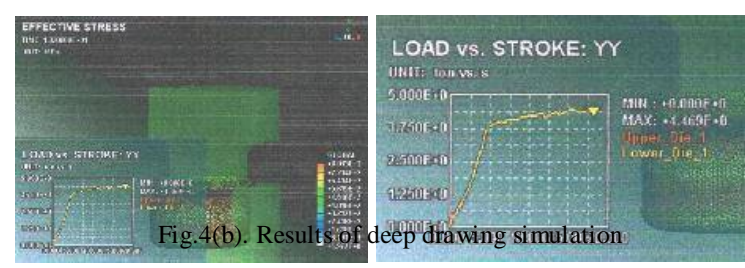

Interpret: With these observations amount \& rate of deformation could be determined and with the graph of Load v/s Stroke, it is possible to determine the capacity of the press. Also with die structural analysis the strength of the die is evaluated and design can be validated.

\section{Open ended experiment 2:}

\section{Title: "Design and simulation of Metal Ruler blank (Blanking \& Piercing Process)".}

\section{Design:}

With regard to the component analysis, the sheet metal component identified is a metal ruler of $24 \mathrm{~mm}$ by $164 \mathrm{~mm}$ length and $1 \mathrm{~mm}$ thick made-up of shearing process. The design calculations includes determining the punch and dies dimensions taking into consideration of cutting clearance, force requirement and preparing the 3D solid models for simulation as part of the Modeling, shown below in fig. 5 .
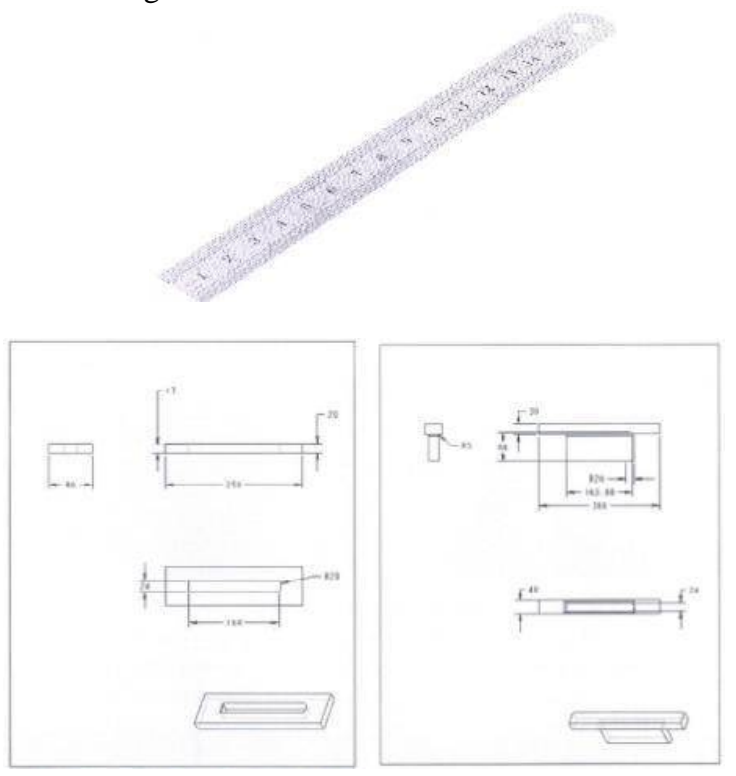

Fig. 5. Metal ruler component and punch \& die models.

Conduct: The 3D models are imported in to the simulation environment of the software and essential input details are assigned such as material, stroke, and friction details. Then with all these inputs simulation is carried-out. 


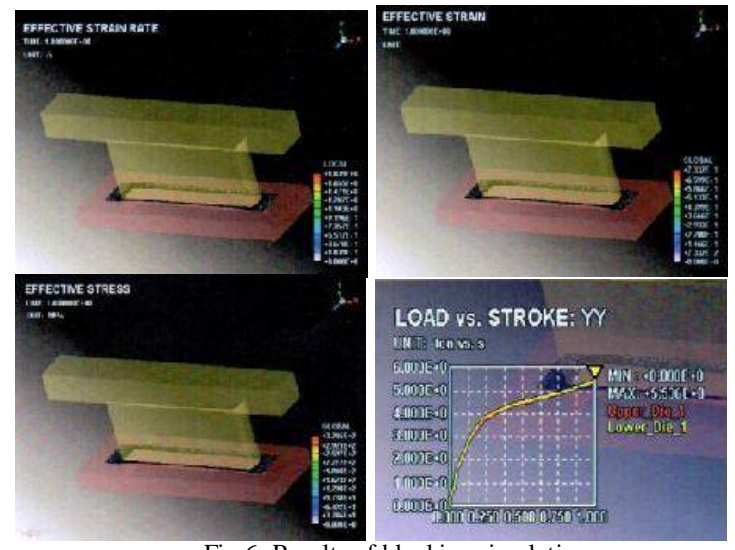

Fig.6. Results of blanking simulation

Analyze: The simulation results are observed for four of the important aspects of forming given in the table 2 for blanking

Table 2. Observation of the blanking simulation

\begin{tabular}{|c|l|l|l|}
\cline { 3 - 4 } S.No. & Description & Unit & Max. Value \\
\hline 1 & Effective Strain & $\mathrm{mm} / \mathrm{mm}$ & 7.332 \\
\hline 2 & Effective Strain Rate & /second & $1.839 / \mathrm{s}$ \\
\hline 3 & Effective Stress & MPa & 324.6 \\
4 & Load v/s Stroke & Ton v/s s & 5.536 \\
\hline
\end{tabular}

Interpret: The force requirement for blanking and piercing could be evaluated based on the load v/s stroke graph and hence selection of suitable press.
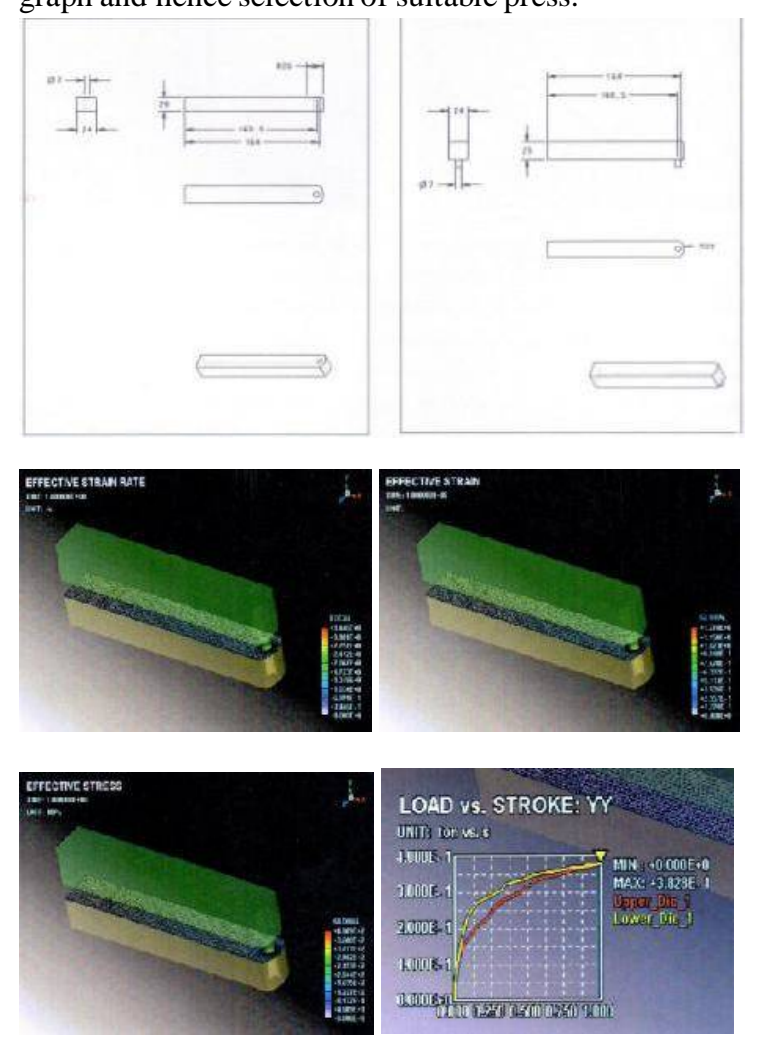

Fig.7. Results of piercing simulation
Table 3. Observation of the piercing simulation

\begin{tabular}{|c|l|l|l|}
\hline S.No. & Description & Unit & Max. Value \\
\hline 1 & Effective Strain & $\mathrm{mm} / \mathrm{mm}$ & 1.278 \\
\hline 2 & Effective Strain Rate & /second & $3.446 / \mathrm{s}$ \\
\hline 3 & Effective Stress & MPa & 408.9 \\
\hline 4 & Load v/s Stroke & Ton v/s s & 0.383 \\
\hline
\end{tabular}

\section{ASSESSMENT}

Assessment has been done for attainment of program outcome $b$ - "Ability to design and perform laboratory experiments for manufacturing \& allied systems as well as to analyze and interpret data" of ABET 3(B) criteria. The outcome element for the outcome are as follows.

i. Design an experiment to verify the conceptual understanding.

ii. Conduct (or simulate) an experiment and report the results.

iii. Analyze a set of experimental data.

iv. Interpret the data.

Students were evaluated for each indicators and the overall attainment is $63.32 \%$ as shown in figure 8

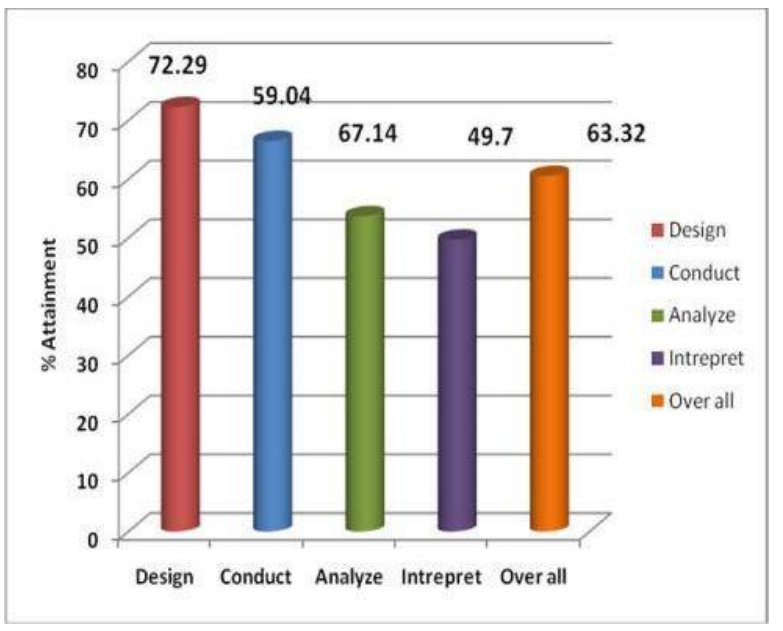

Fig.8 Attainment of program outcome b

\section{CONCLUSION}

Students were able to interpret the results of analysis and could draw the conclusions regarding selection of press, amount and rate of deformation, determination of die structural strength, defect detection, determination of stages required to attain final configuration of the component. This activity helped students to get acquainted with the design process and also lead better understanding of class-room theoretical concepts Overall this activity resulted in cognitive and synergic atmosphere for learning among the students. 


\section{REFERENCES}

1] Lewis, L.H. \& Williams, C.J. (1994). In Jackson, L. \& Caffarella, R.S. (Eds.). Experiential Learning: A New Approach (pp. 5-16). San Francisco: JosseyBass.

2] Moon, J.A. (2004). A Handbook of Reflective and Experiential Learning: Theory and Practice. New York: RoutledgeFalmer.

3] Yang DY, Hug H, Oh SI, Kim YH (eds) (2002) Proceedings of the 5th InternationalConference and Workshop on Numerical Simulation of 3D Sheet Metal Forming Processes- Verification of Simulation with Experiment, Jeju Island

4] Dieter GE, Kuhn HA, Semiatin SL (2003) Handbook of workability and process design. ASM International, Metals Park, $\mathrm{OH}$

5] Banabic D, Dörr RI (1995) Modeling of the sheet metal forming. Transilvania Press, Cluj Napoca (in Romanian)

6] Makinouchi A, Nakamachi E, Onate E, Wagoner RH (eds) (1993) Proceeding of the $2^{\text {nd }}$ International Conference andWorkshop on Numerical Simulation of 3D Sheet Metal Forming Processes, Isehara

7] Karima, M. ,1989, Blank development and tooling design for drawn parts using a modified slip line field based approach, J. Eng. Ind. 111,344 340.

8] Sowerby, R. , Duncan, J.L., Chu, E., 1986, The modeling of sheet metal stampings, Int. J. Mech. Sci. 28 (7) ,414430.

9] Zhaotao, Z., Bingwen, L., 1986, Determination of blank shapes for drawing irregular cups using an electrical analogue method. Int. J. Mech. Sci., 28 (8), 499-503

\section{Acknowledgement}

The authors gratefully acknowledge the support by beloved Students, HOD, Faculty and Staff, Department of Industrial and Production Engineering, Principal and Management of B. V. B. College of Engineering and Technology, Hubli, Karnataka. 